\title{
PCI in Post Thrombolysis Stable STEMI Patients: A Timeline in Question
}

\author{
Irtiza Hasan ${ }^{1,2}$, Tasnuva Rashid ${ }^{3}$, Md. Harun Ur Rashid Bhuiyan ${ }^{4}$ \\ ${ }^{1}$ Cardiology, University of Canterbury Christ Church University, Kent, UK \\ ${ }^{2}$ Internal Medicine, The University of Edinburgh, Edinburgh, UK \\ ${ }^{3}$ Department of Epidemiology, The University of Texas HSC at Houston, School of Public Health, Texas, USA \\ ${ }^{4}$ Clinical \& Interventional Cardiology, Z.H. Sikder Cardiac Care \& Research Centre, Dhaka, Bangladesh \\ Email: *irtiza.hasan@icloud.com
}

Received 26 October 2015; accepted 5 December 2015; published 8 December 2015

Copyright (C) 2015 by authors and Scientific Research Publishing Inc.

This work is licensed under the Creative Commons Attribution International License (CC BY). http://creativecommons.org/licenses/by/4.0/

cC) (i) Open Access

\begin{abstract}
ST elevation myocardial infarction (STEMI) occupies a significant portion of the cardiovascular disease spectrum and poses a continuing challenge on the health care delivery system worldwide. A dilemma exists in the clinical triage system for appropriate strategic modalities of treatment, based on underlying triad of patient-hospital-cardiac pathological factors as well as cut off timelines. Current European Society of Cardiology (ESC) guideline recommends percutaneous coronary intervention (PCI) within 3 to 24 hours in post thrombolysis stable patients. This review critically evaluated the evidences underlying the ESC recommendation. Trials included in this review are SIAM III, GRACIA 1, CAPITAL-AMI, CARESS-IN-AMI, NORDISTEMI, PRAGUE-1, WEST and LEIPZIG. Most of the evidences support the notion for immediate post thrombolysis PCI in stable patients within 1.9 to 2.7 hours, which contradicts the ESC timeline of up to 24 hours. Also, there is a reduced generalizability of the trial results due to differences in the design of the various trials, study population, composite endpoints, variations in drug dose \& formulation, co-administration of pharmacotherapies and type of stents used. This warrants further research for standardization \& optimization of the treatment protocol with respect to post thrombolysis PCI in stable STEMI patients.
\end{abstract}

\section{Keywords}

ST-Elevation Myocardial Infarction (STEMI), Percutaneous Coronary Intervention (PCI), Thrombolysis, European Society of Cardiology (ESC) Guideline

\footnotetext{
${ }^{*}$ Corresponding author.
} 


\section{Introduction}

Acute coronary syndrome (ACS) is an umbrella term for a constellation of clinical symptoms and categoric manifestation of various stages of coronary atherosclerosis including unstable angina (UA), non-ST elevated myocardial infarction (NSTEMI) and ST-elevation myocardial infarction (STEMI) [1] [2]. ACS is a major contributor in cardiovascular disease (CVD) spectrum and is the leading cause of death worldwide for both developed and developing countries [3]. In the United States, every 43 seconds someone suffers from a myocardial infarction (MI) and in every minute someone dies from it [3]. It is postulated that by 2030 , about $40.5 \%$ of the US population will suffer from some form of CVD (especially ACS) with about $61 \%$ increase in total health care cost [4]. On a global scale, ACS is responsible for 50\% of all CVD related deaths [5]. According to a study done in the US in 2009, about 24\% - 40\% of all acute MI admissions were due to STEMI \& rest due to NSTEMI [6].

STEMI is the deadliest among the three presentations of ACS. It is caused by sudden total occlusion of coronary arteries resulting in myocardial necrosis evidenced by raised cardiac biomarkers and ECG changes (ST elevation, Q wave) with substantial risk of death and disability. In the US only, every year there are about 250,000 cases of STEMI, of which about 30\% fail to receive any therapy [7]. Among those who receive Percutaneous Coronary Intervention (PCI), only $40 \%$ are treated within first 90 minutes of symptom onset and those treated with thrombolysis/fibrinolysis, only less than $50 \%$ are done within timeframe (door to needle) of $30 \mathrm{mi}-$ nutes [7]. Further it has been found that mortality in patients with STEMI increases for each 30 minutes without proper intervention [7]. Some studies found that the incidence of STEMI is in a decreasing trend, but a significant portion (12\%) of patients is still dying within 6 months of post diagnosis [8]. A study has projected that timely treatment of patients with STEMI reduced the in-hospital mortality from $11.2 \%$ to $9.4 \%$ [9]. Current treatment guideline emphasizes on early invasive therapy through optimized revascularization or thrombolytic therapy coupled with aggressive management based on evidence provided by randomized controlled trials. This justifies the continuous research and updates in treatment guidelines based on research findings. However, due to non uniform nature in the conduction of various trials, different outcome measures, and difference in the interpretation pose a challenge in the clinical significance and implication of various trial reports and hence the treatment. This paper focuses on the role and timing of post-thrombolytic stable patients based on the ESC guidelines [10].

\section{Pathophysiology \& Management of STEMI}

Relentless and repeated progression of coronary artery plaque formation through phases of endothelial dysfunction, chemotactic inflammatory changes, foam cell and fatty streak formation results in the development of coronary atheroma and atherosclerosis [1] [11]. A fine balance exists between plaque stability and vulnerability factors. A slight shift in balance favors plaque rupture with resultant thrombus formation at site of rupture, propensity for complete occlusion and hence STEMI (as shown in Figure 1).

Diagnosis of STEMI is done mostly based on clinical history, changes in ECG and cardiac enzymes. It is a medical emergency and needs urgent in-hospital care consisting of standard medical care, thrombolysis and revascularization. Medical management and thrombolysis focuses on symptomatic treatment as well as plaque stabilization, prevention of progression of subsequent future events. But revascularization by either PCI or coronary artery bypass grafting (CABG) aims to re-establish coronary artery flow leading to improvement of ischemia and its manifestations [12]. The Urgency of the treatment is based on various pathologic changes in the myocardium following STEMI, which is illustrated in Figure 2.

Strategic modality of treatment and choice of therapy following STEMI is an intricate and fine balance between patient stability, contraindications, critical period of presentation, delay in the onset of management, presence of optimal network of PCI capable hospitals with efficient triage system and 24-hour cardiac catheterization lab with skilled staffs. Usually primary PCI is the gold standard and most preferred reperfusion intervention if performed within 90 to 120 minutes of symptom onset as shown by various trials and meta-analysis [8] [13]-[15]. But in cases where PCI cannot be performed within the critical time or there is lack of access to PCI capable hospital or contraindication to PCI, fibrinolysis is the modality of reperfusion [8] [15] [16] (Figure 3). However, irrespective of time, primary PCI is the dominant reperfusion strategy in Europe as opposed to fibrinolysis and fibrinolysis is done only in 6\% to 8\% of STEMI patients in European countries [17]-[19]. Both procedures have certain complications as depicted in Figure 4 with significant excess risk of stroke, cerebral and non-cerebral hemorrhage with fibrinolytics [8]. Hence due to various contraindications, associated complications 


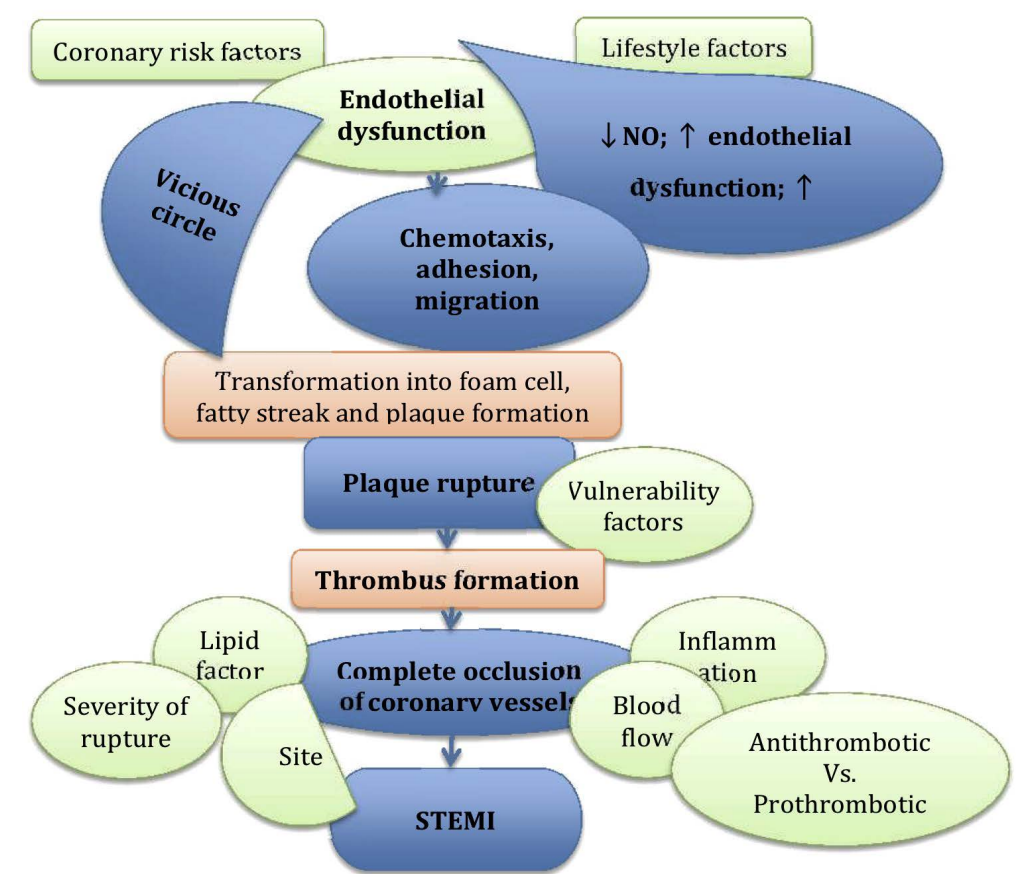

Figure 1. Pathophysiology of STEMI. NO, nitric oxide; $\uparrow$, increase; $\downarrow$, decrease. Various coronary risk factors and modifiable and non-modifiable life style factors results in endothelial dysfunction, which in turn through various sequential stages results in plaque formation. A continued vicious cycle between these two is translated into plaque rupture and thrombus formation with ultimate complete blockage of coronary vessels resulting in STEMI. The symptomatic manifestation of STEMI depends on various factors including site of obstruction, inflammation, patient factors, etc.

\begin{tabular}{|c|c|c|c|c|c|c|c|}
\hline \multicolumn{3}{|c|}{ Early perfusion therapy } & \multicolumn{5}{|c|}{ Late reperfusion; reperfusion injury } \\
\hline \multicolumn{3}{|c|}{ Reversible, viable } & \multicolumn{5}{|c|}{ Irreversible, non-viable } \\
\hline \multicolumn{3}{|c|}{ Necrosis } & \multicolumn{5}{|c|}{$\begin{array}{l}\text { Post necrotic changes, infarction extension, Lt. ventricular } \\
\text { remodeling }\end{array}$} \\
\hline $\begin{array}{l}\text { Coronary } \\
\text { occlusion }\end{array}$ & $\begin{array}{l}\text { Waviness } \\
\text { of fibers }\end{array}$ & Coagulation necrosis & $\begin{array}{l}\text { Contracti } \\
\text { on band, } \\
\text { necrosis }\end{array}$ & $\begin{array}{l}\uparrow \text { Macrophage } \\
\text { infiltration }\end{array}$ & $\begin{array}{l}\text { Granulati } \\
\text { on tissue }\end{array}$ & $\begin{array}{l}\text { Collagen } \\
\text { deposition }\end{array}$ & $\begin{array}{c}\text { Dense } \\
\text { Collagen } \\
\text { scar }\end{array}$ \\
\hline
\end{tabular}

Figure 2. Timeline for myocardial changes in STEMI.

and limited effectiveness, various guidelines postulate the use of fibrinolysis as an adjuvant to PCI with PCI being performed either immediately or following watchful waiting in patients who develop LV dysfunction or severe ischemia.

\section{The ESC Guidelines on Revascularization}

The ESC guidelines for revascularization in 2014 recommend immediate post thrombolysis PCI within 3 to 24 hour of thrombolysis in stable patients rather than watchful waiting. However, question remains about the need of PCI in post thrombolysis stable patients and also the cut off timelines in doing so. This paper will critically review the evidences and actual objectives of different trial, which underlies the ESC recommendations in terms: 1) role of PCI in post thrombolysis stable patients and 2) timing of PCI in post thrombolysis stable patients. 


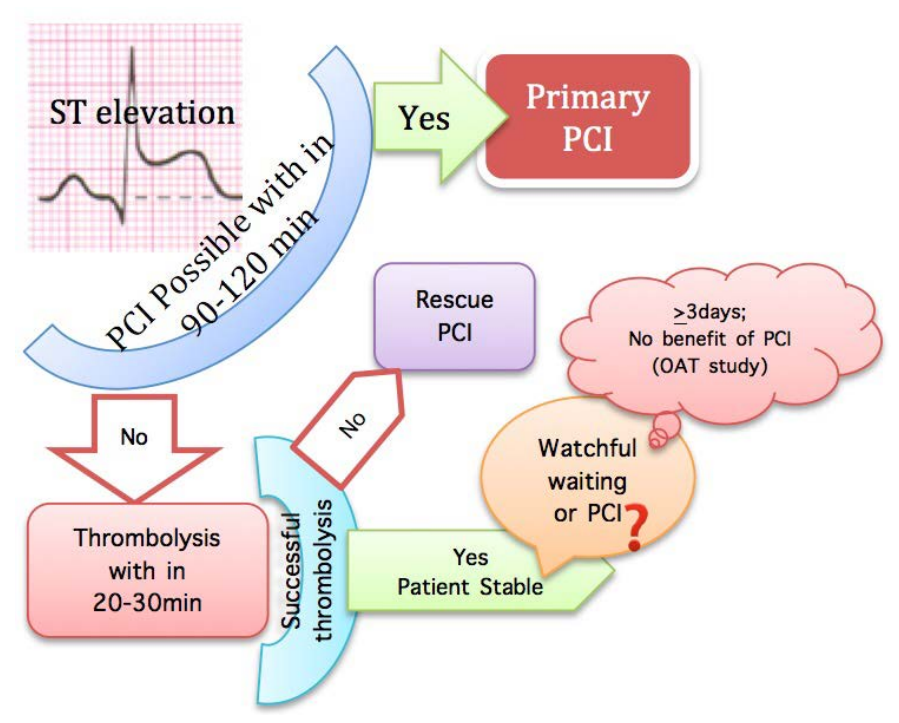

Figure 3. Management of STEMI.

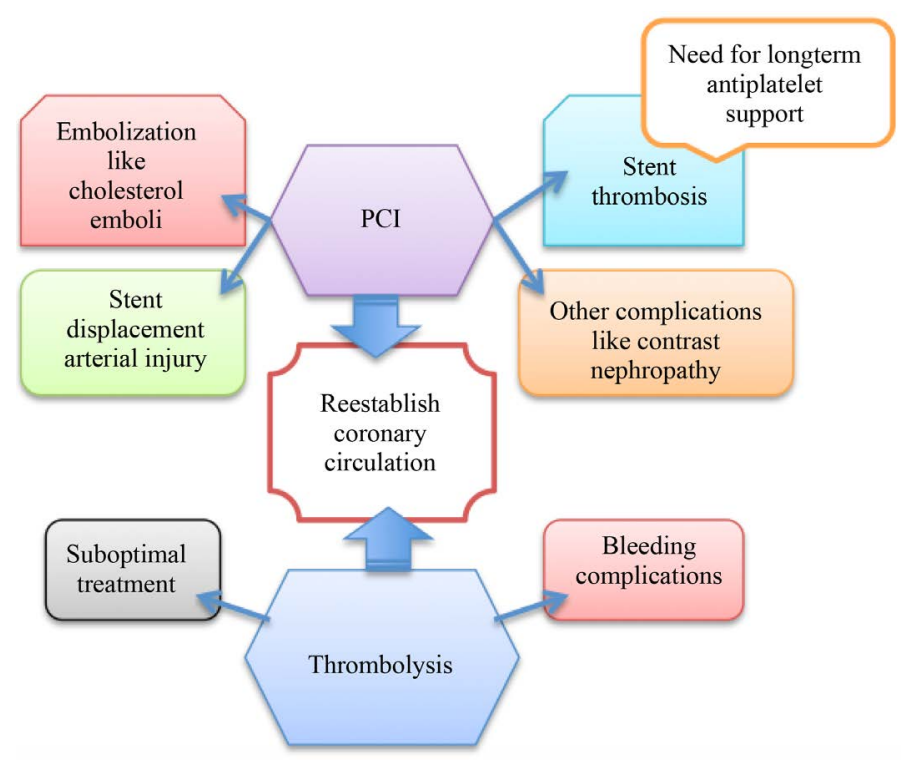

Figure 4. Complication following revascularization.

\section{Review of Evidences}

\subsection{Role of PCI in Post Thrombolysis Stable Patients}

ESC guideline regarding post thrombolytic PCI is based on several trials and meta-analyses done comparing immediate angioplasty with rescue angioplasty. One of the earliest trials looking at the association was SIAM III done on 197 patients with AMI where one group received angioplasty within six hours of thrombolysis with reteplase and the other after two weeks. It was found that the immediate stenting group had a significant decrease in primary endpoint of ischemic event, death, reinfarction and need for revascularization by $25 \%$ [20]. GRACIA 1 is another randomized intent to treat trial, which compared combined endpoints of death, reinfarction and revascularization at 12 months. 500 low to moderate risk STEMI patients were randomly assigned to immediate angioplasty within 6 to 24 hours post thrombolysis group and ischemia guided approach group [21]. PCI was done in $80 \%$ of the intervention group compared to $21 \%$ of conservative group. Though there was no difference in the incidence of cardiac events at 30 days but at one year there was significant decrease of primary endpoint 
in $60 \%$ of intervention group [21].

The CAPITAL-AMI trial, which occurred immediately after GRACIA 1 trial looked at high-risk STEMI patients presenting $\leq 6$ hours after onset of symptoms and thrombolysed with tenecteplase. Similar composite endpoints were compared between full dose of tenecteplase facilitated PCI group (within 3 hours) and tenecteplase alone group at $1 \& 6$ months respectively [22]. Unscheduled PCI was required for $53.7 \%$ of tenecteplase group at 6 months. There was a significant reduction of primary endpoints at 1 and 6 months in facilitated PCI group.

In keeping with preceding trials, another intent to treat trial called CARESS-IN-AMI was done in high risk patients treated with half-dose reteplase and abciximab [23]. The hazard of the primary outcome of composite death, reinfarction and ischemia at 30 days was lower (HR 0.40; 95\% CI 021 - 070) in patients in immediate PCI group compared to rescue PCI group. Another trial looking at similar endpoints at 30 days as the above mentioned trials, found that in tenecteplase treated high risk group patients with STEMI, the risk of primary endpoints was significantly lower in immediate PCI group compared to rescue. PCI was performed in a median of 2.8 hours in intervention group compared to 32.5 hours in standard treatment [24]. In contrary to the above trials, the NORDISTEMI trial which looked at patients living at very far transfer distance to PCI, found no significant difference $(\mathrm{P}=0.19)$ between immediate $\mathrm{PCI}$ and conservative treatment groups with respect to similar primary endpoints including stroke at 1 year [25].

The ESC guideline is also based on 4 meta-analyses. One of the first meta-analysis done by Collet et al. in 2006, looked at difference in composite endpoints of death or reinfarction between early PCI and ischemia guided PCI group [26]. Most of early PCI was done within 2 to 3 hours of fibrinolysis compared to an average of 26 to 30 days in rescue PCI group. Though there was no difference in mortality ( $P=0.64$ ) between the two groups, but there was significant of 2 folds $(\mathrm{P}=0.0006)$ decrease in reinfarction in early PCI group in stent era.

Another systematic review of NORDSTEMI, TRANSFER-AMI, CARESS-IN-AMI, WEST, CAPITAL-AMI, LEIPZIG, GRACIA-1, SIAM III and PRAGUE-1 compared the primary endpoints of death, recurrent non-fatal MI, recurrent ischemia, stroke and major bleeding in period ranging from 1 to 12 months [27]. In most of the trials PCI was performed within 1 to 3.5 hours of fibrinolysis except two trials (13.2 \& 16.7 hours). Among the 9 trials, 2 used half dose of fibrinolysis with most trials using tenecteplase. There was a significant reduction in risk of reinfarction, recurrent ischemia and mortality in the immediate PCI group compared to the conservative group. There was no difference in risk of stroke or major bleeding between the two groups. A meta-analysis done by F. Borgia et al. on 7 of the 9 above mentioned trials found that early PCI significantly reduce rates of reinfarction $(P=0.003)$ and combined endpoints of death, reinfarction \& recurrent ischemia $(P<0.001)$ at 30 days follow up with persistent of result at 6 months $(P=0.01)$ and 1 year follow up [28]. Similar findings were replicated at 30 days for another meta-analysis done by S.P. D'souza et al. on 8 of the above-mentioned trials [29].

\subsection{Timing of PCI in Post Thrombolysis Stable Patient}

According to OAT study, which looked at 4 years cumulative risk of death, reinfarction or heart failure, there was no reduction in risk when PCI was done in stable patients 3 to 28 days post MI compared to medical management [30]. Following this trial and based on many subsequent trials, ESC guideline recommends immediate PCI within 3 - 24 hours of thrombolysis. However, there is a difference in timing at when various trials that underlie the ESC guideline, performed post thrombolysis PCI. For most of the trials including NORDSTEMI, CARESS-IN-AMI, TRANSFER-AMI, CAPITAL-AMI, LEIPZIG, SIAM III and PRAGUE-1, PCI was performed within a median of 1.9 to 2.7 hours post thrombolysis with the exception of WEST \& GRACIA- 1 trials where the median was 13.2 \& 16.7 hours respectively. As such, in majority of the trials the minimum time period was less than 3 hours and for none of the trials it was more than 17 hours with only two trials between the time periods of 3 to 24 hours. Hence, based on only two trials done within the timeframe, it is very difficult to interpolate the results of the trials to a beneficial effect within 3 to 24 hours. Further well-designed studies with larger sample size are needed to be done based on this timeframe of 3 to 24 hours for better generalization of the results.

\section{Discussion}

Various evidences put forth by the different trials and meta-analyses; do support the notion that immediate post thrombolytic PCI has a better prognostic values related to reinfarction or recurrent ischemia compared to 
watchful waiting. However, on careful analysis of the evidences provided it becomes evident that there are certain differences between how the trials are designed and conducted, which reduces the generalizability of the trials. All of the trials looked at primary endpoint as a composite of mortality, reinfarction and recurrent ischemia and hence might not have enough power to look at each individual outcome. Again the cutoff point for diagnosis of various outcome also varied between the trials, like reinfarction was diagnosed at serum CK $>2$ times (CAPITAL AMI) versus $>3$ times upper normal limit (SIAM III) which might create a misclassification of the primary outcome and bias the trial results. The outcomes were evaluated at different time points as 1 month versus 6 months versus 1 year, which reduces the comparability of effect. The timing, dosage and thrombolytic agent also varied among the trials. The timing of thrombolysis varied between 2 hours (NORDISTEMI) to 6 hours (CAPITAL AMI) to <12 hours (SIAM III, CARESS-IN-AMI, GRACIA-1) post symptoms. Two of the trials including CARESS-IN-AMI used half dose of thrombolytic. There was also a variation in type of thrombolytics used. Some of the earlier trials included both stenting era and balloon era which being of different efficacies might bias the result obtained. There is also variation in the use as well as type, dose, frequency and timing of co-administered pharmacotherapies including aspirin, clopidogrel, abciximab, ticlopidine, etc. For most of the trials the time between thrombolysis and PCI varied between 1.9 to 2.7 hours with only two trials at 13.2 and 16.7 hours respectively. Thus, on one hand there was very few trials supporting the 3 to 24 hour time duration as mentioned in the ESC guideline and on the other hand there was no cut off time for maximum benefit. On a different note, the median age of the study participants of all the trials ranged between 57 to 65 years with around $80 \%$ being males. As such the result from this trial cannot be generalized to younger age groups or females or people with comorbidities other than those looked at. Also, due to higher rates of rescue PCI in the watchful waiting group along with intent to treat analysis, there might have been a dilution of the overall effect with chance of lesser difference between the groups in case less rescue PCI. Last but not least some of the trials like CAPITAL AMI, CARESS-IN-AMI looked at high risk groups compared to others which looked at relatively stable patients. As such there is a need for careful weighting of evidences for and against immediate post thrombolytic PCI before generalizing them as treatment guideline.

Though in this paper we tried to evaluate all the trials and meta-analyses underlying the ESC recommendation, however there might be other related trials, which were beyond the scope of this paper. Thus, there is a need for more studies to correctly characterize the role and timeline of PCI in post thrombolysis stable patients.

\section{Conclusion}

Though current evidences show a potential for beneficial role of post thrombolytic PCI compared to watchful waiting in STEMI patients, there is a need for further research to be done in this field. Larger trial with broader inclusion criteria and follow-up is needed to correctly signify the benefits and determining the critical time interval for maximum effect.

\section{References}

[1] Kumar, A. and Cannon, C.P. (2009) Acute Coronary Syndromes: Diagnosis and Management, Part I. Mayo Clinic Proceedings, 84, No. 10.

[2] Yun, D. and Alpert, J. (1997) Acute Coronary Syndromes. Cardiology, 88, 223-237. http://dx.doi.org/10.1159/000177335

[3] Go, A.S., et al. (2013) AHA Statistical Update. Circulation, 129, e28-e292. http://dx.doi.org/10.1161/01.cir.0000441139.02102.80

[4] Heidenreich, P.A., Trogdon, J.G., Khavjou, O.A., et al. (2011) Forecasting the Future of Cardiovascular Disease in the United States a Policy Statement from the American Heart Association. Circulation, 123, 933-944. http://dx.doi.org/10.1161/CIR.0b013e31820a55f5

[5] Turpie, A.G. (2006) Burden of Disease: Medical and Economic Impact of Acute Coronary Syndromes. American Journal of Managed Care, 12, S430.

[6] O’Gara, P.T., Kushner, F.G., Ascheim, D.D., et al. (2013) 2013 ACCF/AHA Guideline for the Management of ST-Elevation Myocardial Infarction: A Report of the American College of Cardiology Foundation/American Heart Association Task Force on Practice Guidelines. Journal of the American College of Cardiology, 61, e78-e140. http://dx.doi.org/10.1016/j.jacc.2012.11.019

[7] AHA (2015) STEMI Systems of Care. 
http://www.heart.org/HEARTORG/HealthcareResearch/MissionLifelineHomePage/LearnAboutMissionLifeline/STEM I-Systems-of-Care_UCM_439065_SubHomePage.jsp

[8] Steg, P.G., et al. (2012) ESC Guidelines for the Management of Acute Myocardial Infarction in Patients Presenting with ST-Segment Elevation. European Heart Journal, 33, 2569-2619. http://dx.doi.org/10.1093/eurheartj/ehs215

[9] Rogers, W.J., Canto, J.G., Lambrew, C.T., et al. (2000) Temporal Trends in the Treatment of over 1.5 Million Patients with Myocardial Infarction in the US from 1990 through 1999: The National Registry of Myocardial Infarction 1, 2 and 3. Journal of the American College of Cardiology, 36, 2056-2063. http://dx.doi.org/10.1016/S0735-1097(00)00996-7

[10] Windecker, S., et al. (2014) 2014 ESC/EACTS Guidelines on Myocardial Revascularization the Task Force on Myocardial Revascularization of the European Society of Cardiology (ESC) and the European Association for Cardio-Thoracic Surgery (EACTS) Developed with the Special Contribution of the European Association of Percutaneous Cardiovascular Interventions (EAPCI). European Heart Journal, 2014, ehu278.

[11] Kleinschmidt, K.C. (2006) Epidemiology and Pathophysiology of Acute Coronary Syndrome. John Hopkins Advanced Studies in Nursing, 4, 72-77.

[12] Nakamura, M. (2010) Angiography Is the Gold Standard and Objective Evidence of Myocardial Ischemia Is Mandatory If Lesion Severity Is Questionable. Indication of PCI for Angiographically Significant Coronary Artery Stenosis without Objective Evidence of Myocardial Ischemia (Pro). Circulation Journal: Official Journal of the Japanese Circulation Society, 75, 204-217. http://dx.doi.org/10.1253/circj.CJ-10-0881

[13] Bonnefoy, E., Lapostolle, F., Leizorovicz, A., Steg, G., McFadden, E.P., Dubien, P.Y., et al. (2002) Primary Angioplasty versus Prehospital Fibrinolysis in Acute Myocardial Infarction: A Randomised Study. The Lancet, 360, 825-829. http://dx.doi.org/10.1016/S0140-6736(02)09963-4

[14] Bonnefoy, E., Steg, P.G., Boutitie, F., Dubien, P.Y., Lapostolle, F., Roncalli, J., et al. (2009) Comparison of Primary Angioplasty and Pre-Hospital Fibrinolysis in Acute Myocardial Infarction (CAPTIM) Trial: A 5-Year Follow-Up. European Heart Journal, 30, 1598-1606. http://dx.doi.org/10.1093/eurheartj/ehp156

[15] Armstrong, P.W., Gershlick, A.H., Goldstein, P., Wilcox, R., Danays, T., Lambert, Y., et al. (2013) Fibrinolysis or Primary PCI in ST-Segment Elevation Myocardial Infarction. New England Journal of Medicine, 368, 1379-1387. http://dx.doi.org/10.1056/NEJMoa1301092

[16] Appleby, P., et al. (1994) Indications for Fibrinolytic Therapy in Suspected Acute Myocardial Infarction: Collaborative Overview of Early Mortality and Major Morbidity Results from All Randomised Trials of More Than. The Lancet, 343 , 311-322.

[17] Gershlick, A.H., Banning, A.P., Myat, A., Verheugt, F.W.A. and Gersh, B.J. (2013) Reperfusion Therapy for STEMI: Is There Still a Role for Thrombolysis in the Era of Primary Percutaneous Coronary Intervention? The Lancet, 382, 624-632. http://dx.doi.org/10.1016/S0140-6736(13)61454-3

[18] Miedema, M.D., Newell, M.C., Duval, S., Garberich, R.F., Handran, C.B., Larson, D.M., et al. (2011) Causes of Delay and Associated Mortality in Patients Transferred with ST-Segment-Elevation Myocardial Infarction. Circulation, 124, 1636-1644. http://dx.doi.org/10.1161/CIRCULATIONAHA.111.033118

[19] Herrin, J., Miller, L.E., Turkmani, D.F., Nsa, W., Drye, E.E., Bernheim, S.M., et al. (2011) National Performance on Door-In to Door-Out Time among Patients Transferred for Primary Percutaneous Coronary Intervention. Archives of Internal Medicine, 171, 1879-1886. http://dx.doi.org/10.1001/archinternmed.2011.481

[20] Scheller, B., Hennen, B., Hammer, B., Walle, J., Hofer, C., Hilpert, V., et al. (2003) Beneficial Effects of Immediate Stenting after Thrombolysis in Acute Myocardial Infarction. Journal of the American College of Cardiology, 42, 634641. http://dx.doi.org/10.1016/S0735-1097(03)00763-0

[21] Fernandez-Avilés, F., Alonso, J.J., Castro-Beiras, A., Vázquez, N., Blanco, J., Alonso-Briales, J., et al. (2004) Routine Invasive Strategy within 24 Hours of Thrombolysis versus Ischaemia-Guided Conservative Approach for Acute Myocardial Infarction with ST-Segment Elevation (GRACIA-1): A Randomised Controlled Trial. The Lancet, 364, 10451053. http://dx.doi.org/10.1016/S0140-6736(04)17059-1

[22] Le May, M.R., Wells, G.A., Labinaz, M., Davies, R.F., Turek, M., Leddy, D., et al. (2005) Combined Angioplasty and Pharmacological Intervention versus Thrombolysis Alone in Acute Myocardial Infarction (CAPITAL AMI Study). Journal of the American College of Cardiology, 46, 417-424. http://dx.doi.org/10.1016/j.jacc.2005.04.042

[23] Di Mario, C., Dudek, D., Piscione, F., Mielecki, W., Savonitto, S., Murena, E., et al. (2008) Immediate Angioplasty versus Standard Therapy with Rescue Angioplasty after Thrombolysis in the Combined Abciximab REteplase Stent Study in Acute Myocardial Infarction (CARESS-in-AMI): An Open, Prospective, Randomised, Multicentre Trial. The Lancet, 371, 559-568. http://dx.doi.org/10.1016/S0140-6736(08)60268-8

[24] Cantor, W.J., Fitchett, D., Borgundvaag, B., Ducas, J., Heffernan, M., Cohen, E.A., et al. (2009) Routine Early Angioplasty after Fibrinolysis for Acute Myocardial Infarction. New England Journal of Medicine, 360, 2705-2718. 
http://dx.doi.org/10.1056/NEJMoa0808276

[25] Bøhmer, E., Hoffmann, P., Abdelnoor, M., Arnesen, H. and Halvorsen, S. (2010) Efficacy and Safety of Immediate Angioplasty versus Ischemia-Guided Management after Thrombolysis in Acute Myocardial Infarction in Areas with Very Long Transfer Distances: Results of the NORDISTEMI (Norwegian Study on District Treatment of ST-Elevation Myocardial Infarction). Journal of the American College of Cardiology, 55, 102-110. http://dx.doi.org/10.1016/j.jacc.2009.08.007

[26] Collet, J.-P., Montalescot, G., May, M.L., Borentain, M. and Gershlick, A. (2006) Percutaneous Coronary Intervention after Fibrinolysis: A Multiple Meta-Analyses Approach According to the Type of Strategy. Journal of the American College of Cardiology, 48, 1326-1335. http://dx.doi.org/10.1016/j.jacc.2006.03.064

[27] Desch, S., Eitel, I., Rahimi, K., de Waha, S., Schuler, G. and Thiele, H. (2010) Timing of Invasive Treatment after Fibrinolysis in ST Elevation Myocardial Infarction-A Meta-Analysis of Immediate or Early Routine versus Deferred or Ischemia-Guided Randomised Controlled Trials. Heart, 96, 1695-1702.

[28] Borgia, F., Goodman, S.G., Halvorsen, S., Cantor, W.J., Piscione, F., May, M.L., et al. (2010) Early Routine Percutaneous Coronary Intervention after Fibrinolysis vs. Standard Therapy in ST-Segment Elevation Myocardial Infarction: A Meta-Analysis. European Heart Journal, 31, 2156-2169. http://dx.doi.org/10.1093/eurheartj/ehq204

[29] D'Souza, S.P., Mamas, M.A., Fraser, D.G. and Fath-Ordoubadi, F. (2011) Routine Early Coronary Angioplasty versus Ischaemia-Guided Angioplasty after Thrombolysis in Acute ST-Elevation Myocardial Infarction: A Meta-Analysis. European Heart Journal, 32, 972-982. http://dx.doi.org/10.1093/eurheartj/ehq398

[30] Hochman, J.S., Lamas, G.A., Buller, C.E., Dzavik, V., Reynolds, H.R., Abramsky, S.J., et al. (2006) Coronary Intervention for Persistent Occlusion after Myocardial Infarction. New England Journal of Medicine, 355, 2395-2407. http://dx.doi.org/10.1056/NEJMoa066139 